\title{
Sistema Faxinal: pesquisa na UNICENTRO e perspectivas de estudos ambientais
}

\section{"Faxinal" systems: research at the UNICENTRO and perspectives of the environmental studies}

\author{
Edivaldo Lopes Thomaz \\ Universidade Estadual do Centro Oeste
}

\begin{abstract}
Resumo: Este ensaio tem por objetivo delinear o estudo do Sistema Faxinal (SF) por pesquisadores da UNICENTRO, caracterizar faxinais a partir de dados secundários e apontar tendências de estudos com enfoque ambiental. A produção sobre Faxinal na UNICENTRO cresceu significativamente a partir de meados dos anos 2000. Além disso, essa produção apresenta diversidade de abordagem sendo realizada no âmbito de três departamentos: História, Engenharia Florestal e Geografia. Os faxinais existentes atualmente são heterogêneos por se localizaremem diferentes sistemas ambientais. Propõem-se estudos ambientais em SF a partir de dois enfoques: tipológico (escala pequena) e processos ambientais (escala grande). O desafio da investigação dos processos ambientais é conhecer a dinâmica biofísica, estabelecer parâmetros e geobioindicadores de qualidade e degradação ambiental em Faxinal e aplicar métodos e técnicas para conservação de recursos naturais em áreas de faxinais.
\end{abstract}

Palavras-chave: Sistema agrosilvopastoril. Processos ambientais. Metodologia.

Abstract: This paper aims to describe the study of the "Faxinal" System (SF) performed by the UNICENTRO researchers. It also seeks to typify "faxinal" areas based on secondary data and to point out trends of the environmental studies. The scientific production at the UNICENTRO regarding "faxinal" areas has significantly grown since the mid 2000s. Moreover, this production displayed a variety of approaches distributed among three departments: History, Forest Engineering and Geography. The currently "faxinal" areas are heterogeneous, since they are spread across different environmental systems. Environmental studies in SF are proposed from two perspectives: typological (small scale) and environmental processes (large scale). The main challenges of the environmental processes investigation are to recognize the biophysical dynamics, to establish a set of biophysical parameters, and to provide geo- and bioindicators of the environmental quality and degradation, as well as to apply methods and techniques for natural resources conservation in "faxinal" areas.

Keywords: Agro-forestry-pasture system. Environmental processes. Methodology. 


\section{INTRODUÇÃO}

Durante o I Simpósio de Pesquisadores de Faxinais: Estado da Arte e Perspectivas, realizado em Julho na Universidade Estadual de Ponta Grossa - UEPG discutiu-se a pesquisa contemporânea em Faxinais, assim como as perspectivas destes estudos. Nesse simpósio verificou-se também que quase toda produção relacionada ao tema Faxinal é produzida por pesquisadores vinculados as Universidades, Estadual do Centro-Oeste do Paraná (UNICENTRO) e Estadual de Ponta Grossa (UEPG), seguida da Universidade Federal do Paraná. No caso da Universidade Estadual do Centro Oeste do Paraná (UNICENTRO) isto ocorre devido a sua realidade multicampi (Irati e Guarapuava), coincidir com a região de existência de Faxinais.

O Sistema Faxinal (SF) é um sistema agrosilvopastoril em que as terras de pastoreio são utilizadas coletivamente no interior da Floresta Ombrófila Mista (criadouro comunitário). Enquanto as áreas de plantar são cultivadas de forma individual. OSistema Faxinal é prevalente no Estado do Paraná e se estende particularmente sobre a área de domínio da Floresta Ombrófila-mista. Existe quantidade significativa de SF com variadas condições sociais, culturais, econômicas e ambientais (IAP, 2004). Dessa forma, este ensaio tem por objetivo delinear o estudo do SF por pesquisadores da UNICENTRO, caracterizar faxinais a partir de dados secundários e apontar tendências de estudos com enfoque ambiental realizado pelo Grupo de Pesquisa em Hidrogeomorfologia. Este ensaio é uma versão estendida de uma comunicação apresentada, no I Simpósio de Pesquisadores de Faxinais: Estado da Arte e Perspectivas.

\section{PROCEDIMENTO DE COLETA E ANÁLISE DE DADOS}

A produção científica foi pesquisada por meio do software PublishorPerish $(\mathrm{C}$ (HARZING, 2007) que usa a base do Google Scholar (Google Acadêmico). A partir deste software palavras-chave foram utilizadas para a busca: Faxinal, Sistema Faxinal, Sistema de Faxinal e UNICENTRO. O resultado foi filtrado e classificado por data, sendo considerado apenas artigo científico. Em seguida, por meio do Qualis-CAPES levantaram-se as revistas nas quais são divulgadas as pesquisas da UNICENTRO. Outro recurso utilizado foi o levantamento de pesquisadores atuando em pesquisa em SF a partir da base de dados da Plataforma Lattes.

Por fim, o relatório técnico, Levantamento preliminar sobre o Sistema Faxinal no Estado do Paraná (IAP, 2004), foi analisado estatisticamente (ex. análise de agrupamento) no sentido de levantar as condições dos SF e apontar possibilidades de pesquisas ambientais, corroborando com os estudos realizados pelo Grupo de Pesquisa em Hidrogeomorfologia. A análise do referido relatório foi realizada pós-evento. Os dados foram tabulados utilizando-se os seguintes parâmetros: nome do Faxinal, área do criadouro, número de famílias, qualidade ambiental, relação criadouro/ areal total, pressão demográfica relativa, pressão demográfica relativa do criadouro e total de animais. Alguns parâmetros foram incluídos ou transformados, por exemplo, a situação atual geral da conservação ambiental aparece no relatório de modo qualitativo (ótima, boa, regular, ruim e péssima) essa classificação foi transformada em valores numéricos de 1 (ótima) a 5 (péssima). Outro parâmetro transformado foi a pressão demográfica sobre os Faxinais levantado no relatório (número de famílias/área do Faxinal). Os dados foram analisados por meio do software BioEstat 5.0 e Past. 


\section{PRODUÇÃO CIENTÍFICA NA UNICENTRO REFERENTE AO TEMA FAXINAL}

Desde o início de 1970 havia atividade de ensino superior em Guarapuava e Irati nas antigas Faculdade de Filosofia, Ciências e Letras de Guarapuava (FAFIG) e Faculdade de Educação, Ciências e Letras de Irati (FECLI). Contudo, a UNICENTRO se constituiu como universidade no final dos anos de 1990. Por conseguinte, o aumento das pesquisas relacionadas ao SF, como veremos, está ligado ao crescimento da universidade a partir dos anos 2000 (Figura 1).

Até 2007 apenas nove trabalhos $(22,5 \%)$ foram publicados referindo-se de alguma forma ao SF. A grande "explosão" ocorreu entre 2008 a 2011, em que $31(77,5 \%)$ trabalhos foram divulgados. Entretanto, o conjunto de trabalhos produzidos tem baixa citação (total 14) o que representa em torno de 0,34 citações artigo/ano.
No ano de 2000 foi defendida a tese (NERONE, 2000), Terras de Plantar, Terras de Criar - Sistema Faxinal: Rebouças - 19501997, junto ao Programa de Pós-Graduação da Faculdade de Ciências e Letras da Universidade Estadual Paulista, Campus de Assis, São Paulo. O referido trabalho como se observou no I Simpósio de pesquisadores de faxinais tornou-se um clássico sobre pesquisa de Faxinal.

Em sua tese, a autora discute a origens do Sistema Faxinal na Península Ibérica e sua implantação no Estado Paraná, explica a posse e uso da terra no Sistema Faxinal, trata de questões da organização e do trabalho comunitário e doméstico no Faxinal, assim como aspectos de sociabilidade e manifestações culturais e religiosas entre outros temas. Este trabalho parece abrir as pesquisas de faxinais na área de abrangência da UNICENTRO. Entretanto, a sua divulgação apenas como tese não é suficiente para torná-lo mais acessível.

Figura 1 - Evolução do termo Faxinal nas pesquisas da UNICENTRO



Nota: No ano de 2011 o levantamento foi realizado até junho. 
A produção científica tem sido divulgada majoritariamente em revistas paranaenses (Quadro 01). Apenas duas revistas fora do Estado do Paraná (Floresta e Revista Sociedade e Natureza) publicaram pesquisas realizadas na UNICENTRO. Por outro lado, a classificação das revistas no QUALIS-CAPES indica, em sua maioria, médio a baixo impacto. À primeira vista o tema SF interessa apenas aos pesquisadores paranaenses, por serem as pesquisas publicadas em língua portuguesa e em revistas regionais.

Quadro 01 - Revistas onde foram divulgadas as pesquisas realizadas na UNICENTRO

\begin{tabular}{|l|c|}
\hline \multicolumn{1}{|c|}{ Revista } & Qualis/Área \\
\hline Ambiência & B3 (Interdisciplinar) \\
\hline Ciências Exatas e Naturais & B4 (Interdisciplinar) \\
\hline Ciência Florestal & A2 (Serviço Social) \\
\hline Emancipação & B3 (Interdisciplinar) \\
\hline Floresta & B2 (Interdisciplinar) \\
\hline Geografia (Londrina) & B2 (Interdisciplinar) \\
\hline Ra 'e Ga & - \\
\hline Revista Espaço, Tempo e Linguagem & B1 (História) \\
\hline Revista de História Regional & B2 (Interdisciplinar) \\
\hline Revista Sociedade \& Natureza & B4 (Interdisciplinar) \\
\hline Terr@Plural & \\
\hline
\end{tabular}

Fonte: QUALIS-CAPES (Junho de 2011)

Nota: Foi incluída a área de maior classificação da revista

Anteriormente, viu-se o nítido aumento de produção científica relacionada ao tema Faxinal. Entretanto, onde têm sido produzidos os estudos sobre o SF no âmbito da UNICENTRO? Pesquisa realizada com base na Plataforma Lattes indicou 174 currículos pesquisadores nos quais o termo Faxinal aparece como palavra-chave freqüente. Deste total, 13 pesquisadores da UNICENTRO aparecem com freqüência relativa acima de $60 \%$. Os pesquisadores que estudam SF são provenientes dos cursos de História (38,5\%), Engenharia Florestal (15,5\%) e Geografia (46\%). Se anteriormente o trabalho clássico de Nerone (2000) teve origem no departamento de História (Guarapuava), atualmente a produção origina-se no departamento de História em Irati, assim como mais dois departamentos emergem com produtores de estudos em SF.

A pesquisa em SF na UNICENTRO apresenta maior diversidade do que o verificado em outras universidades. Isto ocorre por existir um maior número de pesquisadores envolvidos com a temática em três departamentos distintos. Portanto, torna-se difícil estabelecer o estado da arte sobre o assunto. Entretanto, indicam-se exemplos de pesquisa e extensão realizadas no âmbito dos departamentos que servem como exemplos de estudos na referida temática (Quadro 2, 3 e 4). 
Quadro 02 - Pesquisadores da UNICENTRO que estudam a temática Faxinal

\begin{tabular}{|l|c|}
\hline \multicolumn{1}{|c|}{ Pesquisador (a) } & $\begin{array}{c}\text { Frequência relativa } \\
\text { do Termo Faxinal }\end{array}$ \\
\hline 2. Maria Magdalena Nerone (H) & 92 \\
\hline 7. José AdilçonCampigoto (H) & 84 \\
\hline 8. Valdemir Antoneli (G) & 84 \\
\hline 11. Valter Martins (H) & 77 \\
\hline 14. Cecilia Hauresko (G) & 75 \\
\hline 15. Hélio Sochodolak (H) & 72 \\
\hline 16. Luciano Farinha Watzlawick (E.F) & 72 \\
\hline 20. Gabriela Schmitz Gomes (E.F) & 70 \\
\hline 23. Edivaldo Lopes Thomaz (G) & 69 \\
\hline 26. Sergio Fajardo (G) & 67 \\
\hline 31. Jair Antunes (H) & 66 \\
\hline 41. Aparecido Ribeiro de Andrade (G) & 64 \\
\hline 43. Marquiana de Freitas Vilas Boas & 64 \\
Gomes (G) & \\
\hline
\end{tabular}

Fonte: Plataforma Lattes (2011)

Nota: O número indica a posição do pesquisador em relação aos 174 pesquisadores ranqueados; H (História); G (Geografia); E.F (Engenharia Florestal).
No caso do departamento de História, as pesquisas estão voltadas para os aspectos sociais e culturais do SF. Além disso, o programa de pós-graduação em sua área de concentração (História e regiões) e linha de pesquisa (Regiões: práticas socioculturais e relações de poder) contempla este tema enfocando práticas socioculturais de povos tradicionais (ex. indígenas, quilombolas, Faxinalenses e outros) (Site Mestrado em História, 2011).

A pesquisa em Engenharia Florestal tem enfoque no manejo sustentável dos recursos florestais (florestas nativas e plantadas). Alguns temas de pesquisa são voltados para os aspectos florísticos em floresta Ombrófila Mista (composição e diversidade), dinâmica de carbono, dinâmica de regeneração em floresta e espécies para fins medicinais.

Quadro 03 - Exemplos de estudos realizados no âmbito da UNICENTRO

\begin{tabular}{|l|c|}
\hline \multicolumn{1}{|c|}{ Produção científica } & Departamento \\
\hline $\begin{array}{l}\text { SOCHODOLAK, H.; CAMPIGOTO, J. A. Estudos em história cultural na região sul do Paraná. } \\
\text { Guarapuava: UNICENTRO, 2008. 298 p. }\end{array}$ & História \\
\hline $\begin{array}{l}\text { CAMPIGOTO, J. A.; BONA, A. N. A hermenêutica e a origem dos faxinais. Revista de História } \\
\text { Regional, v. 14, p. 127-153, 2009. }\end{array}$ & História \\
\hline $\begin{array}{l}\text { ALBUQUERQUE, J. M.; WATZLAWICK, L. F.; MESQUITA, N. S. Efeitos do uso em Sistema Faxi- } \\
\text { nal na florística e estrutura em duas áreas da Floresta Ombrófila Mista no município de Rebouças, } \\
\text { PR. Ciência Florestal, v.. 21, n. 2, p. 323-334, 2011. }\end{array}$ & Engenharia Florestal \\
\hline $\begin{array}{l}\text { PEDROSO, K.; WATZLAWICK, L. F.; OLIVEIRA, N. K.; VALÉRIO, A. F.; GOMES, G. S. ; SILVES- } \\
\text { TRE, R. Levantamento de plantas medicinais arbóreas e ocorrência em Floresta Ombrófila Mista. } \\
\text { Ambiência (UNICENTRO), v. 3, p. 39-50, 2007 }\end{array}$ & Engenharia Florestal \\
\hline $\begin{array}{l}\text { HAURESKO, C.; FERREIRA, E. R.. A manutenção de práticas tradicionais e a adoção de inovações } \\
\text { nas comunidades Faxinalenses do Paraná. In: Darlene Aparecida de Oliveira Ferreira \& Enéas Ren- } \\
\text { te Ferreira. (Org.). Geografia e território: interpretações do espaço brasileiro. 1 ed. Rio Claro - SP: } \\
\text { Editora da Pós-graduação em Geografia, 2010, v. 1, p. 153-172. }\end{array}$ & Geografia \\
\hline $\begin{array}{l}\text { DIAS, W.; THOMAZ, E. L.. Avaliação dos efeitos do pastoreio sobre a erosão de margens de canal } \\
\text { fluvial em Faxinal. Sociedade \& Natureza (UFU. Impresso), v. 23, p. 23-35, 2011a. }\end{array}$ & Geografia \\
\hline
\end{tabular}

Fonte: Plataforma Lattes (2011).

Porsua vez, no departamento deGeografia as pesquisas são realizadas em duas áreas de especialidades: Geografia Humana e Geografia Física. Em Geografia Humana os estudos possuem enfoque sociocultural. Na Geografia Física (Grupo de Hidrogeomorfologia) os estudos têm por objetivo investigar a interação entre a sociedade e o ambiente, especialmente, no que se refere às derivações antropogenéticas nos processos hidrogeomorfológicos que emergem no Sistema Faxinal.

Assim, temas como: dinâmica de sedimento, erosão e degradação do solo, 
bioerosão e hidrologia florestal (ex. adicionamento de serrapilheira, interceptação de chuva, atravessamento de chuva, infiltra- ção de água no solo etc.) são frequentes nas pesquisas realizadas pelo Grupo de Hidrogeomorfologia.

Quadro 04 - Exemplo de projetos de extensão realizados no âmbito da UNICENTRO

\begin{tabular}{|l|c|}
\hline \multicolumn{1}{|c|}{ Projetos de Extensão } & Departamento \\
\hline $\begin{array}{l}\text { Memória das práticas e conhecimentos tradicionais sobre o uso coletivo e a preservação das águas } \\
\text { e mananciais em territórios Faxinalenses. }\end{array}$ & História \\
\hline $\begin{array}{l}\text { Apiário Rio de Mel: Implantação de uma Unidade Demonstrativa de Produção e Beneficiamento } \\
\text { Apícola na UNICENTRO, Campus de Irati. }\end{array}$ & Engenharia Florestal \\
\hline $\begin{array}{l}\text { Resgate de Práticas agrícolas tradicionais através da identificação de potenciais usos da biodiver- } \\
\text { sidade local. }\end{array}$ & Geografia \\
\hline
\end{tabular}

Fonte: Pró-Reitoria de Extensão e Cultura (2011).

\section{PERSPECTIVAS DE ESTUDOS AMBIENTAIS EM SISTEMA FAXINAL}

Em 1997, o Governo do Estado do Paraná reconheceu oficialmente o Sistema Faxinal e seu papel na manutenção do patrimônio cultural além de conciliar atividades agrosilvopastoris com a conservação ambiental, incluindo a proteção da Araucaria angustifolia (pinheiro-do-paraná). O conceito de Sistema Faxinal é definido:

$\S 1^{\circ}$ - Entende-se por Sistema Faxinal: o sistema de produção camponês tradicional, característico da região Centro-Sul do Paraná, que tem como traço marcante o uso coletivo da terra para produção animal e a conservação ambiental. Fundamenta-se na integração de três componentes: a) produção animal coletiva, à solta, através dos criadouros comunitários; b) produção agrícola - policultura alimentar de subsistência para consumo e comercialização; c) extrativismo florestal de baixo impacto - manejo de erva-mate, araucária e outras espécies nativas (DECRETO ESTADUAL N. . 3.446/97).

Poucos anos após o Decreto Estadual existiam no Estado do Paraná 44 Faxinais preservando suas características de um total de 152 (IAP, 2004). Segundo o mesmo relatório outras 56 áreas permaneciam apenas como paisagem de mata de araucária sendo que em apenas $35,8 \%$ delas o estado de conservação era bom ou ótimo. Enquanto que em 52 áreas restantes transformaram-se em comunidades de agricultores individuais. Esta desestruturação atingiu uma taxa aproximada de $36,8 \%$ por década (1994-2004).

Furtado et al. (2003) estabeleceu por meio de análise fatorial ranqueamento dos Faxinais no Estado do Paraná. Os autores analisaram 20 faxinais a partir de 80 variáveis socioeconômicas e culturais. Os resultados apontaram o Faxinal Ivaí-Anta Gorda como um dos de melhor qualidade $\left(2^{\circ}\right)$ e Rio Bonito como o de pior qualidade $\left(20^{\circ}\right)$. No relatório do IAP (2004) esses faxinais aparecem com grau de conservação ambiental regular. Tal perspectiva de análise multivariada deve ser aplicada também em estudos ambientais.

Ao analisar a matriz de correlação (Quadro 05) baseada em sete variáveis representando 40 faxinais observa-se de maneira geral uma baixa correlação entre as variáveis. Um dos objetivos dessa matriz foi verificar como as variáveis analisadas influenciam a conservação ambiental dos faxinais. As maiores correlações positivas são obtidas entre a área do Faxinal (variável 1) e do criadouro (variável 2) e entre o número de famílias residentes (variável 3). 
Ou seja, o tamanho do Faxinal e criadouro influenciam a quantidade de pessoas que ocupam a área. Assim, é de se esperar relação com a conservação ambiental (variável 4) e pressão demográfica relativa em relação a área do criadouro - PDRC (variável 7). Verificou-se que quanto maior a pressão demográfica relativa em relação à área do criadouro ocorreu piora no estado de conservação do Faxinal ( $r=0,507)$.

Quadro 05 - Matriz de Correlação de Pearson obtida de parâmetros de 40 Faxinais (IAP, 2004)

\begin{tabular}{|c|c|c|c|c|c|c|c|}
\hline Matriz & 1 & 2 & 3 & 4 & 5 & 6 & 7 \\
\hline 1 & 1,000 & --- & --- & --- & --- & --- & --- \\
\hline 2 & 0,832 & 1,000 & --- & --- & --- & --- & --- \\
\hline 3 & 0,666 & 0,713 & 1.000 & --- & --- & --- & --- \\
\hline 4 & $\begin{array}{c}0,019 \\
\text { (ns) }\end{array}$ & $\begin{array}{c}-0,045 \\
(\mathrm{~ns})\end{array}$ & $\begin{array}{c}0,183 \\
\text { (ns) }\end{array}$ & 1,000 & --- & --- & --- \\
\hline 5 & $\begin{array}{c}-0,166 \\
\text { (ns) }\end{array}$ & $\begin{array}{c}0,246 \\
\text { (ns) }\end{array}$ & $\begin{array}{c}-0,038 \\
\text { (ns) }\end{array}$ & $\begin{array}{c}-0,197 \\
\text { (ns) }\end{array}$ & 1,000 & --- & --- \\
\hline 6 & $-0,485$ & $-0,421$ & $\begin{array}{c}-0,012 \\
\text { (ns) }\end{array}$ & 0,327 & $\begin{array}{c}0,153 \\
\text { (ns) }\end{array}$ & 1,000 & --- \\
\hline 7 & $\begin{array}{c}-0,244 \\
\text { (ns) }\end{array}$ & $-0,402$ & $\begin{array}{c}0,189 \\
\text { (ns) }\end{array}$ & 0,507 & $-0,514$ & 0,561 & 1,000 \\
\hline
\end{tabular}

Nota: 1) área total do Faxinal; 2) área do criadouro; 3) número de famílias; 4) conservação ambiental; 5) relação entre criadouro/ área total; 6) pressão demográfica relativa em relação área total; 7) pressão demográfica relativa em relação área do criadouro. Os índices 6 e 7 foram obtidos pela divisão da área pelo número de família.

ns: relação estatística não significante ao nível de confiança de $5 \%$.

Os 40 faxinais analisados são heterogêneos (Figura 2 e Quadro 6). Por meio da análise exploratória foi possível estabelecersete grupos, considerando as ligações da direita para esquerda. Estes agrupamentos podem indicar Faxinais prioritários para estudos ambientais.

Grupo 1 (Faxinais:1, 5, 26 e 39) são caracterizados por apresentar áreas muito grande $2088 \pm 812$ mil hectares (média \pm desvio padrão) e grande quantidade de famílias residentes $220 \pm 123$. A PDRC é baixa $14,8 \pm 4,4 \%$ e a conservação

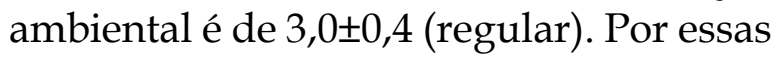

condições a conservação ambiental deveria ser melhor.

Grupo 2 (Faxinais:8, 14, 28, 37, 13, 22, 24, 19,36 e 27) - são caracterizados por apresentar áreas média 504,6 $\pm 63,5$ hectares e quantidade média de famílias residentes 74t58. A PDRC é média/baixa $22,1 \pm 14,9 \%$ e a conservação ambiental é de 2,7 $\pm 0,8$ (regular).

Grupo 3 (Faxinais:3, 7, 4 e 38) - são caracterizados por apresentar áreas pequenas/ médias com256,7 $\pm 24,5$ hectares e quantidade de famílias residentes em torno de $56 \pm 20$. A PDRC é média 25,4 $48,9 \%$ e a conservação ambiental é de 2,7 $\pm 0,6$ (regular).

Grupo 4 (Faxinais:9, 16, 31, 20, 10, 32 e 15) - são caracterizados por apresentar áreas pequenas com $172,1 \pm 69,8$ hectares e quantidade de famílias residentes em torno de $55 \pm 14$. A PDRC é alta 54,0 $023,6 \%$ e a conser-

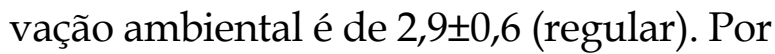
essas condições a conservação ambiental deveria ser pior.

Grupo 5 (Faxinais: 6, 18, 21, 12 e 34) são caracterizados por apresentar áreas pequenas $40,4 \pm 17,7$ hectares e pequena quantidade de famílias residentes 15 \pm 12 . A PDRC é alta 53,0 $041,1 \%$ e a conservação

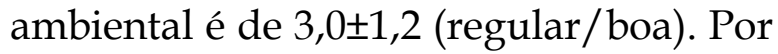
essas condições a conservação ambiental deveria ser pior.

Grupo 6 (Faxinais: 11, 35, 30 e 40) - são caracterizados por apresentar grandes áreas $769,3 \pm 112,8$ hectares e quantidade média de famílias residentes $88 \pm 24$. A PDRC é baixa $12,9 \pm 2,7 \%$ e a conservação ambiental é de 2,5 50,7 (boa).

Grupo 7 (Faxinais: 17, 23 e 29) - são caracterizados por apresentar áreas muito grandes $1331,0 \pm 175,8$ hectares e quantidade média de famílias residentes $82 \pm 28$. A PDRC é alta $14,4 \pm 6,7 \%$ e a conservação ambiental é de 2,7士0,6 (regular). Por essas condições a conservação ambiental deveria ser melhor.Destoam dos grupos anteriores os faxinais 33, 25 e 2 por apresentarem as maiores PDRC 66,7\%; 104,1\% e 258,3\%. 
Figura 2 - Análise exploratória de agrupamento em 40 Faxinais existente de acordo com o Relatório do IAP (2004).

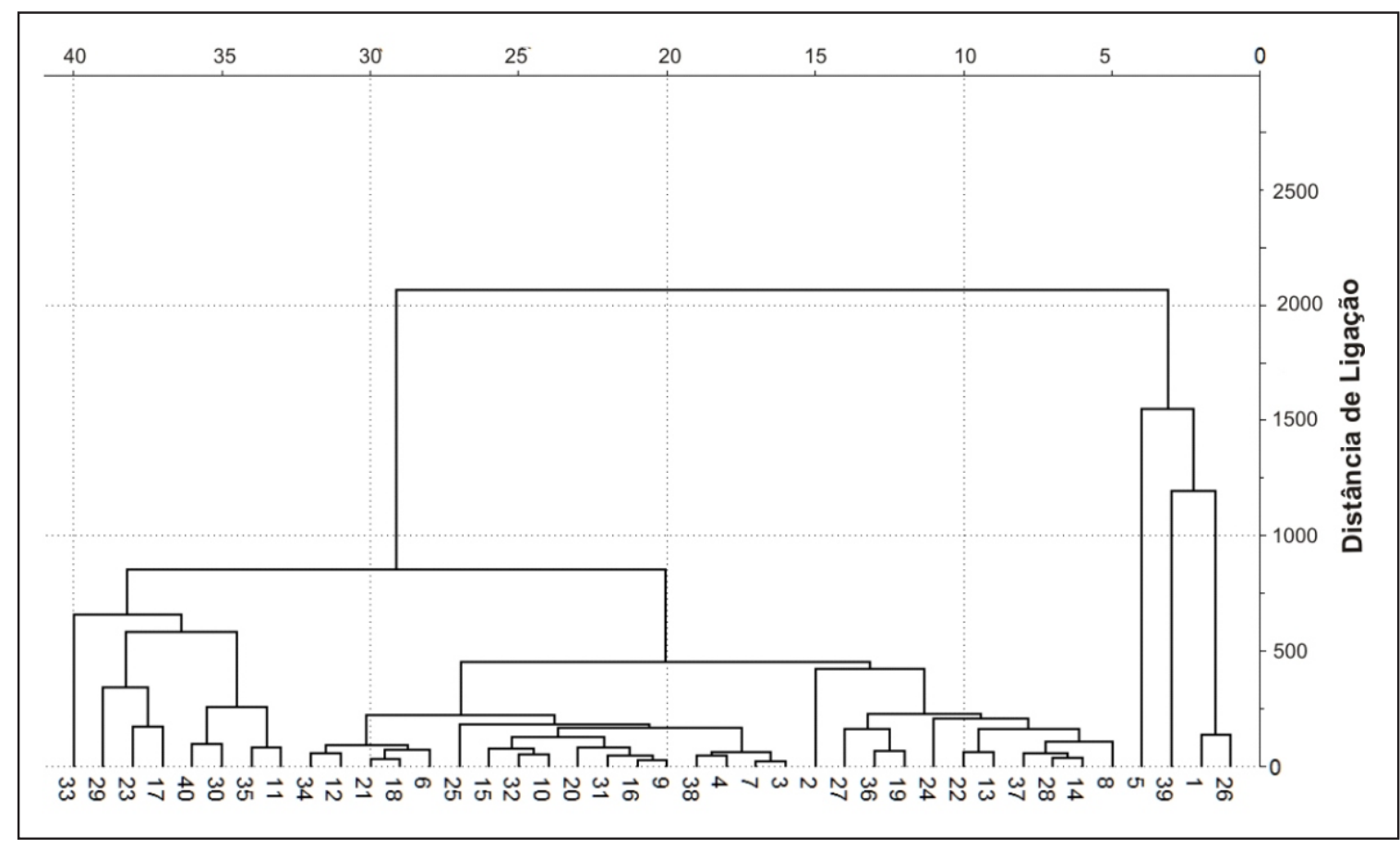

Nota: números indicam os faxinais analisados conforme Quadro 05

Estudos sobre SF têm privilegiado os aspectos: econômico, político, social e cultural. Apenas $23 \%$ das pesquisas realizadas em SF tratam de temas do meio biofísico (Site Pesquisa em Faxinal, 2011). Existe um descompasso entre os avanços das pesquisas socioculturais em relação às do meio biofísico. Portanto, para uma boa compreensão holística do SF os estudos de cunho ambiental devem ser aprofundados.

$\mathrm{Na}$ figura 3 apresenta-se um esboço metodológico para estudos ambientais em SF composto de dois níveis: 1) tipológico (escala pequena); e 2) processos ambientais (escala grande ou de detalhe). Os dois níveis podem ser executados de forma independente ou de modo integrado.

OSF tendea desestruturação (CHANG, 1988, IAP, 2004). Assim, na região Central do Estado do Paraná, podemos encontrar áreas de Faxinais (original - estágio 1), áreas desestruturadas que preservam apenas a paisagem de floresta Ombrófila Mista (estágio 2) e num estágio maior de desagregação chega-se às comunidades de agricultores tradicionais (estágio 3).

Neste caso os estudos podem ser realizados em escalas de 1:25.000 ou menor tendo como objetivo criar tipologias de paisagens em faxinais, bem como sua evolução ao longo dos três estágios ora comentado (Ex. unidades de terras; fragmentos, mosaicos de terrenos e padrões paisagísticos e dinâmica do uso da terra). Nesta abordagem destacam-se os estudos de Ecologia da Paisagem com uso de mapeamento e análise multivariada (TRICART, 1977, KLINK, 1981, NEEF, 1984, FORMAN e GODRON, 1986, BRAUDY, 1989, ZONNEVELD, 1989, GREGORY,1992, FORMAN e WILSON, 1995).

As principais aplicações neste nível de investigação estão, por exemplo, indicação de áreas para recuperação de zonas 
ripárias, recuperação de áreas degradadas, conexão de fragmentos florestais, formação de corredores ecológicos etc. Além disso, este nível permite o estabelecimento de área prioritária para estudos de processos ambientais em escala de detalhe (caso de estudo ou área piloto).

Quadro 06 - Relação dos 40 Faxinais utilizados na análise exploratória (IAP, 2004)

\begin{tabular}{|c|c|c|c|}
\hline Número & Nome do Faxinal & Número & Nome do Faxinal \\
\hline 1 & Água Amarela de Cima (AO) & 21 & Manduri (SMS) \\
\hline 2 & Água Clara de Baixo (Q) & 22 & Mansani (IM) \\
\hline 3 & Água Quente dos Meiras (RA) & 23 & Marcondes $(\mathrm{P})$ \\
\hline 4 & Avencal Barco (Mdb) & 24 & $\begin{array}{l}\text { Marmeleiro de Baixo } \\
\text { (R) }\end{array}$ \\
\hline 5 & Barra bonita $(\mathrm{P})$ & 25 & $\begin{array}{l}\text { Marmeleiro de Cima } \\
\text { (R) }\end{array}$ \\
\hline 6 & Barreiro (Ip) & 26 & Papanduva de Baixo $(\mathrm{P})$ \\
\hline 7 & Cachoeira do Palmital (P) & 27 & Paraná-Anta Gorda (P) \\
\hline 8 & Campestre Paulas (Mdb) & 28 & $\begin{array}{l}\text { Rio Azul dos Soares } \\
\text { (RA) }\end{array}$ \\
\hline 9 & Carriel $(\mathrm{T})$ & 29 & Rio Branco (R) \\
\hline 10 & Emboque (SMS) & 30 & Rio do Couro (I) \\
\hline 11 & Espigão Meleiro (Mdb) & 31 & Salto (R) \\
\hline 12 & Faxina dos Betin (Ib) & 32 & São Gabriel (Q) \\
\hline 13 & Faxinal dos Krüger (BVSR) & 33 & São Miguel (IM) \\
\hline 14 & Faxinal dos Melos (I) & 34 & São Roquinho $(\mathrm{Ph})$ \\
\hline 15 & Guanabara $(\mathrm{P})$ & 35 & $\begin{array}{l}\text { Saudade Santa Anita } \\
\text { (T) }\end{array}$ \\
\hline 16 & Itapará (I) & 36 & $\begin{array}{l}\text { Sete Saltos de Baixo } \\
\text { (PG) }\end{array}$ \\
\hline 17 & Ivaí-Anta Gorda (P) & 37 & Taboãozinho $(\mathrm{P})$ \\
\hline 18 & Lageado de Baixo (M) & 38 & Taquari (RA) \\
\hline 19 & Lageados dos Melos (RA) & 39 & Tijuco Preto $(\mathrm{P})$ \\
\hline 20 & Lagoa dos Ferreiras (Mdb) & 40 & Tronco Ilha (Mdb) \\
\hline
\end{tabular}

Fonte: IAP (2004)

Nota: (AO) Antônio Olinto; (Q) Quitandinha; (RA) Rio Azul; (Mdb) Mandirituba; (P) Prudentópolis; (Ip) Ipiranga; (T) turvo; (SMS) São Mateus do Sul; (Ib)Imbaú; (BVSR) Boa Ventura do São Roque; (I) Irati; (M) Mallet; (R) Rebouças; (IM) Inácio Martins; (Ph) Pinhão; (PG) Ponta Grossa. 
Figura 3 - Esboço metodológico para estudo ambiental em Sistema Faxinal

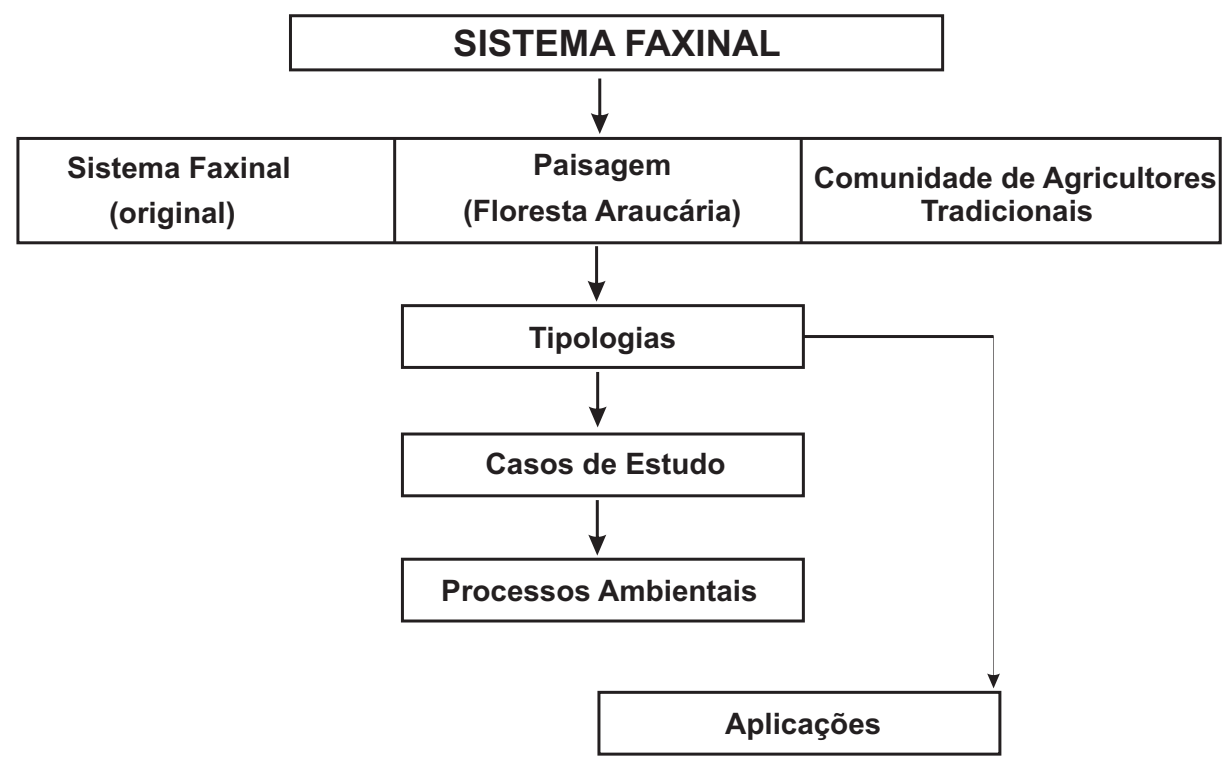

Nos casos de estudo são eleitos áreas ou faxinais prioritários para estudos detalhados (ex. projeto pilotos voltados para manejo ou implantação de atividade econômica). Por fim, os estudos de processos ambientais envolvem: processos geomorfológicos, hidrológicos, pedológicos e ecológicos no âmbito de áreas de faxinais, estejam às aéreas de Faxinais em qualquer um dos três estágios descritos acima. Alguns exemplos de pesquisa de processos ambientais que serão indicadas estão sendo desenvolvidas pelo Grupo de Pesquisa em Hidrogeomorfologia.

a. Circulação de água em Faxinal (Hidrologia Florestal). Notamos que a interceptação de chuva (10,5\%) em floresta secundária foi abaixo da média da interceptação registrada em outros ecossistemas brasileiro e mundial. Um dos motivos para este comportamento é que o manejo em florestas pode causar a desestruturação interna (bosque e sub-bosque), especialmente, nas áreas utilizadas para pastoreio, como é o caso do Faxinal na região Centro Sul do Estado do Paraná (THOMAZ e ANTONELI, 2011 (submetido)). Portanto, estudos comparativos devem ser realizados em áreas florestais (nativas e plantadas) no sentido de avaliar a entrada de água no sistema, pois é a partir dela que outros processos ocorrem (ex. erosão do solo).

b. Adicionamento de serrapilheira. A serrapilheira desempenha papel importante na retenção de água, adicionamento de matéria orgânica no solo, alimento para a fauna entre outros. A interceptação de chuva obtida em serrapilheira em Floresta Ómbrofila Mista em Guarapuava durante dois eventos pluviométricos (82,4 e 76,8 mm) foi de $2,7 \pm 0,29 \%$ e a retenção de umidade pela serrapilheira alcançou 132,9 $98,7 \%$ (THOMAZ e VITOR, 2003). Thomaz (2007) constatou que em floresta secundária a serrapilheira estocada foi de 12,5 t/ ha, e em floresta de araucária o estoque de serrapilheira chegou a 22,6 t/ha. É possível, que o manejo exercido em SF altere o adicionamento de serrapilheira no piso da floresta e, por consequência, influencie em outros subprocessos relacionados à serrapilheira (ex. matéria orgânica, retenção de água e estabilidade de agregados).

c. Biogeomorfologia (Bioerosão). $\mathrm{O}$ Faxinal é um sistema agrosilvopastoril, 
sendo o criadouro comum uma de suas peculiaridades. Praticamente inexiste estudo sobre a capacidade de suporte de animais neste sistema. No relatório do IAP de 2004, apenas em 12 Faxinais havia a quantidade de animais do criadouro comum. Entretanto, efeitos do pastoreio nas terras altas, nas zonas ripárias e nos canais fluviais estão sendo documentados (ANTONELI e THOMAZ, 2009, THOMAZ e DIAS, 2009, DIAS e THOMAZ, 2011a, DIAS e THOMAZ, 2011b). Grosso modo, o pastoreio causa compactação do topo solo, aumenta o escoamento devido à redução da infiltração, o pisoteio expõe o topo do solo, altera a geometria hidráulica de canais e aumenta a entrada de material nos corpos hídricos (ex. matéria orgânica e sedimento). Outro processo influenciado pelo pastoreio é a supressão de rebrota dificultando a regeneração de espécies no interior da floresta. Este processo leva ao "envelhecimento da vegetação do Faxinal" (agricultor comunicação pessoal).

d. Estradas não pavimentadas. Em áreas florestadas e rurais as estradas não pavimentadas têm se constituído nas principais fontes de sedimento (THOMAZ et al., 2010, THOMAZ et al., 2011, THOMAZ e PEREIRA, 2011 (submetido)). As estradas alteram a circulação de água e sedimento através da paisagem (LUCE e WEMPLE, 2001). Por fim, as estradas aumentam a conectividadee a transferência de sedimento e contaminante das vertentes para o canal fluvial (THOMAZ et al., 2011). A dinâmica das estradas nos processos ambientais em áreas de Faxinais precisa ser mais bem compreendida.

e. Dinâmica da terra em agricultura tradicional. O SF apresenta também terra de plantar, além disso, a desestruturação do sistema leva a outros tipos de uso da terra, por exemplo, fumicultura (ANTONELLI e THOMAZ, 2010, ANTONELI, et al., 2011(submetido)). Nas áreas de prevalência de Faxinal ou em áreas de transição (ex. estágio 1 e 2 ), sobretudo, em terras marginais (baixa aptidão agrícola), a prática de roça-de-toco é comum. Neste tipo de uso os agricultores roçam uma gleba de terra, deixam a capoeira secar, queimam e plantam na cinza. O rodízio de terras varia de 3 a 5 anos, ou seja, a mesma área só será utilizada após este período de regeneração. Este tipo de roça é importante para a produção de alimentos, contudo, o efeito da rotação de terra e uso do fogo sobre os processos hidrogeomorfológicos de vertente, degradação e erosão do solo precisa ser mais investigado (THOMAZ, 2007, THOMAZ, 2008, THOMAZ, 2009, THOMAZ, 2011a, THOMAZ, 2011b).

Corroboramos a ideia dos estudos ambientais realizados pela Geografia Física atual enfocar os padrões ambientais estruturado pelos sistemas humanos(GREGORY et al., 2002).Aliás, o sistema agrosilvopastoril (SF)pode ser compreendido como um sistema adaptativo onde ocorre forte interação entre o ambiente e a sociedade. A interação sociedade e ambiente é mediada pela tecnologia. Desta interação emerge a paisagem cultural, bem como os impactos biofísicos (MATTHEWS e HERBERT, 2008). Assim, é nessa perspectiva que os estudos ambientais em Faxinais devem ser conduzidos.

\section{CONSIDERAÇÕES FINAIS}

Pesquisadores da Universidade Estadual do Centro-Oeste têm contribuído significativamente no estudo do Sistema Faxinal. A produção científica é diversificada, sendo realizada em três departamentos: História, Engenharia Florestal e Geografia. A existência de programa de pós-graduação nos três departamentos deverá ampliar os estudos em áreas de Faxinais. 
A partir de dados secundários verificou-se que os Faxinais analisados são heterogêneos e exigem estratégia para 0 estudo ambiental. Diante disso, indicou-se uma metodologia para estudos ambientais em SF composta de dois níveis: 1) tipológica (escala pequena); e 2) processos ambientais (escala grande ou de detalhe). Os dois níveis podem ser executados de forma independente ou de modo integrado.

O Sistema Faxinal é um sistema agrosilvopastoril, portanto, problemas emergem da interação sociedade e ambiente nesse sistema adaptativo. Consequentemente, o desafio da investigação tipológica é criar classificações de faxinais de acordo com o estado de conservação (ex. solo, água, floresta e padrões de paisagens), já os estudos de processos ambientais devem conhecer a dinâmica biofísica no SF, estabelecer parâmetros e geobioindicadores de qualidade e de degradação ambiental em Faxinal e aplicar métodos e técnicas para conservação de recursos naturais em áreas de Faxinais.

\section{AGRADECIMENTOS}

Ao Prof. Dr. Aparecido Ribeiro de Andrade e Profa. Dra. Cecilia Hauresko pela coleta de material para apresentação da comunicação no evento I Simpósio de Pesquisadores de Faxinais: Estado da Arte e Perspectivas.

\section{REFERÊNCIAS}

ALBUQUERQUE, J. M.; WATZLAWICK, L. F.; MESQUITA, N.S. Efeitos do uso em sistema faxinal na florística e estrutura em duas áreas da Floresta Ombrófila Mista no município de Rebouças, PR. Ciência Florestal (UFSM. Impresso), v. 21, p. 323334, 2011.

ANTONELI, V.; THOMAZ, E. L. CANALI, N.; E.A influência da fumicultura na dinâmica da paisagem rural na bacia do Arroio Boa VistaGuamiranga-Paraná. Boletim de Geografia (UEM) (em avaliação), 2011.
ANTONELI, V.; THOMAZ, E. L. Comparação de infiltração de água no solo mensurada em período seco e úmido, em diferentes usos da terra na bacia do arroio Boa Vista, Guamiranga (PR). Ambiência (UNICENTRO), v. 5, p. 301-318, 2009.

ANTONELI, V.; THOMAZ, E. L. Relação entre o cultivo de fumo (Nicotina tabacum L.) e a produção de sedimento na Bacia do Arroio Boa Vista, Guamiranga PR. Geografia (Rio Claro, Impresso), v. 2, p. 383-398, 2010.

BRAUDY, J. Interactions between agricultural and ecological systems at the landscape level. Agriculture, Ecosystemsand Environment, n. 27, p. 119-130, 1989.

CAMPIGOTO, J. A.; BONA, A. N. A hermenêutica e a origem dos faxinais. Revista de História Regional, v. 14, p. 127-153, 2009.

CHANG, M. Y. Sistema faxinal: organização camponesa em desagregação no centro sul do Paraná. IAPAR, bol. téc., 22, Londrina, 1988.

DECRETO ESTADUAL No3.446/97 (25/07/ 1997). Cria as Áreas Especiais de Uso Regulamentado - ARESUR no Estado doParaná e dá outras providências.

DIAS, W.; THOMAZ, E. L. Avaliação dos efeitos do pastoreio sobre a erosão de margens de canal fluvial em sistema de faxinal. Sociedade \& Natureza (UFU. Impresso), v. 23, p. 23-35, 2011 a.

DIAS, W. ; THOMAZ, E. L. Influência de escombros lenhosos na dinâmica de riachos em área de faxinal. Terr@ Plural (UEPG. Impresso), 2011b.

FORMAN, R. T.; GODRON, M. Landscape ecology. New York: John Wiley and Sons, 1986.

FORMAN, R. T.; WILSON, E. O.Land Mosaics: The Ecology of Landscapes and Regions. Publisher: Cambridge University Press, 1995.

FURTADO, M. E.; NETO, A. C.; DOMINGUES, Z. H.; HOSOKAWA, R. T. Ranqueamento de faxinais do Estado do Paraná através da análise fatorial. Revista Ciências Exatas e Naturais, Vol. 5, n. 1, p. 85-99, 2003.

GREGORY, K. J. A natureza da geografia física. São Paulo: Bertrand Brasil, 1992.

GREGORY, K. J.; GURNELL, A. M.; PETTS, G.E. Restructuring physical geography. Transaction Institute of British Geographers. n. 27, p. 136-154, 2002. 
HARZING, A.W. Publish or Perish, available from http://www.harzing.com/pop.htm.2007.

HAURESKO, C.; FERREIRA, E. R. A manutenção de práticas tradicionais e a adoção de inovações nas comunidades faxinalenses do Paraná. In: Darlene Aparecida de Oliveira Ferreira \& Enéas Rente Ferreira. (Org.). Geografia e território: interpretações do espaço brasileiro. 1 ed. Rio Claro - SP: Editora da Pós-graduação em Geografia, 2010, v. 1, p. 153-172.

INSTITUTO AMBIENTAL DO PARANA. Levantamento preliminar sobre o Sistema Faxinal no Estado do Paraná. Relatório de Consultoria Técnica, 2004.

KLINK, H. J. Geoecologia e regionalização natural: bases para pesquisa ambiental. Biogeografia, n. 17, p. 1-32, 1981.

LUCE, C. H.; WEPLE, B.C. Introduction to special issue on hydrologic and geomorphic of forest roads. Earth Surface Processes and Landforms, v. 26, p.111-113, 2001.

MATTHEWS, J. M.; HERBERT, D. T. Geography: a very short introduction. Oxford: University Press, 2008.

NEEF, E. D. Applied landscape research. Applied Geography and Development, v. 24, p. 38-58, 1984.

NERONE, M. M. Terras de Plantar, Terras de Criar - Sistema Faxinal: Rebouças - 1950-1997. 2000.286f. (Doutorado em História) - Programa de PósGraduação da Faculdade de Ciências e Letras da Universidade Estadual Paulista, Campus de Assis, São Paulo, 2000.

PEDROSO, K. ; WATZLAWICK, L. F.; OLIVEIRA, N. K.; VALÉRIO, A. F.; GOMES, G. S. ; SILVESTRE, R .Levantamento de plantas medicinais arbóreas e ocorrência em Floresta Ombrófila Mista. Ambiência (UNICENTRO), v. 3, p. 39-50, 2007.

Pesquisa em Faxinais. Site de divulgação de pesquisas em faxinais. http:/ / faxinais.wordpress. com/indice/ (acessado 16/10/2011).

Site Mestrado em Engenharia Florestal. http:// www.unicentrocienciasflorestais.com/site/ (acessado 16/10/2011).

Site Mestrado em História.http:/ / www.unicentro. br/posgraduacao/mestrado/historia/ (acessado 16/10/2011).

SOCHODOLAK, H.; CAMPIGOTO, J. A. Estudos em história cultural na região sul do Paraná. Guarapuava: UNICENTRO, 2008.

THOMAZ, E. L. The influence of traditional steep land agricultural practices on runoff and soil loss.
Agriculture, Ecosystems\&Environment (Print), v . 130, p. 23-30, 2009.

THOMAZ, E. L. Compartimentos geomorfológicos e produção de milho em agricultura de subsistência, Guarapuava-PR: avaliação exploratória. Sociedade \& Natureza (UFU. Impresso), v. 19, p. 45-54, 2007.

THOMAZ, E. L. Efeito da temperatura na repelência de água no solo: ensaio em laboratório. Revista Brasileira de Recursos Hídricos, v. 13, p. 57-64, 2008.

THOMAZ, E. L. Efeito do sistema de rotação de terra nos processos de vertente - Guarapuava-PR. Geousp (USP), v. 1, p. 111-116, 2011 a.

THOMAZ, E. L. Influência do fogo nos processos hidrológicos e geomorfológicos em solo subtropical. Chamada de Projetos $n^{\circ}$ 05/2011/Programa Universal - Pesquisa Básica e Aplicada (submetido). 2011b.

THOMAZ, E. L. Mudanças nas características físicas do topo do solo causados por erosão laminar em agricultura de subsistência no sistema de rodízio de terras, Gurapuava/PR. Geosul (UFSC), Florianópolis, v. 22, p. 67-94, 2007.

THOMAZ, E. L. The influence of traditional steep land agricultural practices on runoff and soil loss. Agriculture, Ecosystems \& Environment (Print), v. 130, p. 23-30, 2009.

THOMAZ, E. L.; ANTONELI, V.Avaliação de interceptação de chuva em fragmento secundário de ombrófila mista (Faxinal), Guarapuava, PR. Ciência Florestal (em avaliação). 2011.

THOMAZ, E. L.; ANTONELI, V.; DIAS, W. . Estimativa de proveniência de sedimento em cabeceira de drenagem com alta densidade de estradas rurais não pavimentadas. Revista Brasileira de Recursos Hídricos, v. 16, p. 25-37, 2011.

THOMAZ, E. L.; DIAS, W. Bioerosão - considerações sobre a evolução do rebanho bovino brasileiro e suas implicações nos processos geomorfológicos. Revista Brasileira de Geomorfologia, v. 10, p. 3-11, 2009.

THOMAZ, E. L.; PEREIRA, A. A. Escoamento superficial e produção de sedimento e em estrada rural não pavimentada. Revista Brasileira de Geomorfologia (submetido). 2011.

THOMAZ, E.L.; VESTENA, L.R.; ANTONELI, V. Avaliação do aporte de sedimento proveniente de estradas rurais e de seus impactos na descarga sólida fluvial em suspensão, na bacia do rio Guabiroba, Guarapuava-PR. (Relatório de Pesquisa, Edital 475161/2007-6), 2010. 
THOMAZ, E. L.; VITOR, M. R. Caracterizaçãode serrapilheira em Floresta Temperada com Araucária - Guarapuava - PR. In: I SEMINÁRIO DE PESQUISA EM GEOGRAFIA FÍSICA, 1, São Paulo, dezembro 2003. Perspectivas da pesquisa em Geografia Física. Universidade de São Paulo, 2003. v. 1, p 201-207.

TRICART, J. Ecodinâmica. FIBGE/SUPREN, Rio de Janeiro, 1977.

ZONNEVELD, I. S. The land unity: a fundamental concept in landscape ecology, and its applications. Landscape Ecology, v. 3, n. 2, p. 67-86, 1989.

Recebido em: 18/09/11 Aceito em: 08/12/11 